\title{
Competency-based evaluation in a clinical practices course for first-year osteopathic medical students
}

\author{
CHRISTOPHER D. OLSON, D.O. \\ MARY PAT MANN, Ed.S. \\ Athens, Ohio
}

\begin{abstract}
The information explosion
in medicine has created a need to specify carefully what medical students must know. Competency-based education offers a method for doing this, but it is not widely implemented in medical schools. A competency-based approach to evaluation was used for 2 years in a clinical skills course for firstyear osteopathic medical students. Learning objectives were identified. Students were required to demonstrate mastery of the most critical objectives on written and practical examinations. Student ratings and interviews with faculty suggest that the approach is successful in focusing on critical material. The most significant disadvantage was the difference from methods more commonly used, which caused increased anxiety for students and faculty. Improving communication with both groups may be the most productive approach to gaining acceptance.
\end{abstract}

The information explosion in medicine has medical educators in a quandary: What do student physicians need to know, and what is no longer needed? The American Association of Colleges of Osteopathic Medicine $^{1}$ recently completed a project that developed competency-based objectives for undergraduate osteopathic clinical education. Their approach emphasizes the development of skills as well as knowledge, and the analysis of on-the-job performance to select objectives. At the same time, less than 10 percent of medical schools worldwide have attempted to define a set of objectives, and less than 3 percent use them coherently. ${ }^{2}$

Evaluating students, particularly in areas of clinical competence, is another problem. The Association of American Medical Colleges Panel on the General Professional Education of the Physician $(\text { GPEP })^{3}$ recommends that procedures and explicit criteria for systematically evaluating the clinical performance of students should be developed and adopted by medical faculties. Yet little has been done in this area. In fact, only one competencybased program appears regularly in medical education journals-the "Systemwide objectives-based instruction" used at the Southern Illinois University School of Medicine. 4-6 $^{-6}$

The limited use of competency-based instruction in medical education can be attributed to a variety of factors, including lack of specific guidelines, ${ }^{6}$ doubts about their efficacy, ${ }^{6}$ the limited amounts of time and energy faculty can devote to instructional development, 6,8 and resistance to any change in existing modes of teaching and learning. ${ }^{7}$ Implementation of this approach will depend on learning more about how, when, and why it works. ${ }^{9}$ Developing competency-based approaches for medical education means experimenting, evaluating, and sharing the results with fellow educators.

This article presents the results of 2 years of innovation (1984-1985) with competency-based evaluation in an introductory clinical skills course for first-year osteopathic medical students. We will describe the methods used, how they evolved, and the results of evaluations by students and faculty. 


\section{The course}

The Ohio University College of Osteopathic Medicine (OU-COM) introduces students to clinical skills through a sequence of six courses-Osteopathic Clinical Practice (OCP) I through VI. Each OCP course is divided into sections, as follows: History and physical; Psychosocial aspects; Osteopathic principles and practice; Public health and preventive medicine; and Gerontology. Sections are team-taught by family physicians assisted by other physicians, psychologists, nurses, and health care workers. Course time devoted to sections ranges from 1 to 30 hours. The OCP courses overall cover 6 to 12 student hours per week.

We focus here on OCP III, which is presented in the third quarter of the first year. The course teaches psychomotor skills such as osteopathic structural diagnosis and manipulative treatment, psychosocial skills such as family interviewing, and clinical knowledge such as stages of psychologic development. Twelve instructors make presentations, with additional faculty assisting in laboratories and examinations.

Students spend 6 hours per week in class, including 2 hours in structural diagnosis and treatment laboratories. Students work with simulated patients to learn family interviewing, sexual history taking, and breast examination. Other teaching methods include lectures, discussion, independent study, and computer-assisted learning. Students develop skills for coping with death and dying through problem-solving exercises. They also solve patient management problems that focus on prevention and the use of community agencies to assist in patient education and care.

OCP III exemplifies fundamental dilemmas in medical education today, that is, a large and diverse body of content in which new findings compete with traditional topics, and a need for objective evaluations of students that incorporate assessment of clinical skills. These characteristics led the first author (CDO), course coordinator for OCP III, to develop a competency-based approach for the course.

Specific guidelines from the SIU program ${ }^{4}$ were used in OCP III: (1) Students receive the objectives before instruction begins; (2) competencies tested are those specified in the objectives; (3) criteria for acceptable performance are specified ahead of time and do not depend on performance of peers (that is, there are no grading curves); (4) students have many opportunities to achieve competence; and (5) assistance with remediation is available. It was hoped that application of this approach to critical course content would improve retention of such material. As an educational goal, a high level of retention of specific material seemed preferable to retention of a random 70 percent of essential and supplemental material presented in a course.

\section{Methods of implementing the approach}

Implementation of the competency-based approach focused more on testing than teaching strategies. This was appropriate for the administrative structure of the course, in which the course coordinator has a limited impact on teaching methods but more direct control over testing and grading policies.

During the fall of 1983 , the course coordinator met formally and informally with faculty to review the new procedures. Before the quarter began, faculty received a letter describing the course structure. They were asked to do the following: prepare objectives for each presentation of course material; divide them into "competency" and "discriminatory" (those objectives that would be used to discriminate between A, B, and C students) categories; give students a written list of all objectives at or before each presentation; and submit test questions based on the objectives. Competency objectives should be realistic for first-year medical students and important in medical practice. Similar procedures were followed in 1984 to assist faculty in preparing for the course.

Most presentations had existing objectives. Faculty worked to separate objectives that defined critical skills and concepts from less vital outcomes. To pass the course, students were required to pass competency-based tests on the critical competency objectives. The remaining discriminatory objectives became the basis for test questions used to determine a grade beyond passing.

\section{Strategies for testing}

Each year, students took two written and two practical examinations. Written examinations had two roughly equal parts: (1) a competency section, in which each student had to achieve the designated mastery level to pass the test; and (2) a discriminatory section used to assign letter grades at or above $\mathrm{C}$. These examinations included multiple choice, short answer, and essay questions, and were comparable in length to tests used in previous OCP III courses.

Setting the mastery criterion for the written examinations was difficult. In 1984, to ensure that all competency objectives were mastered, the level was set at 95 percent. After negative reactions from some students and faculty and subsequent discussion with a testing consultant, the criterion was lowered to 90 percent for 1985 . This level gave a 10 
percent allowance for extraneous errors within the testing system (for example, ambiguous test items).

Students had three opportunities to demonstrate competence. Retests included only questions related to objectives missed on the last attempt. The criterion for passing remained the same. Testing students only on missed objectives occasionally led to problems: In some cases, students had to reach 90 percent on a 4-question retake.

Practical examinations tested psychosocial and psychomotor skills as performed with simulated patients and were entirely competency based. Faculty and student teaching fellows observed and graded these examinations, as in all OCP courses. Students were tested only on a sample of this material, but they did not know prior to the examination which skills they would demonstrate. For example, one student took a history for breast cancer while another took a sexual history; one student examined and treated a simulated patient with a structural "problem" in the elbow, while another examined and treated a structural "problem" in the thoracic spine.

The first year, students received grading check sheets for each area a week before the final practical examination. To benefit both students and faculty test proctors, the check sheets specified required performance as definitively as possible. However, it is recognized that such tests always involve examiner interpretation and judgment.

In the second year, students received the scoring check sheets at the beginning of the quarter. The first practical test became a "practice practical," to help students understand the level of performance expected of them on the final examination. This provided an opportunity for students to practice their skills in the test situation and for faculty to discuss how to grade students.

Students passed the practicals if they had no more than one error in each of four major segments-History, Examination, Treatment (manipulation), and Psychosocial (dress, rapport, opening and closing, et cetera). Again, students had three opportunities to demonstrate competence. Faculty and student teaching fellows were available to assist students in reviewing material to prepare for both practical and written tests.

Retests covered only those segments not passed the first time, but required demonstration of competence in the area failed and, for the first retry, another related area (for example, examination of the elbow and thorax), and two other areas (examination of the elbow, thorax, and shoulder) for the second retry. This procedure ensured that students actually knew the material and did not "bone up" just on areas failed.

\section{Results of course evaluations}

\section{Student evaluations}

At the end of each quarter, students at OU-COM evaluate their courses. They receive rating forms during one of the last class meetings and complete them at that time. The forms ask for anonymous ratings of course content and process and of instructor performance, and provide space for written comments. This standard evaluation was completed for both years (1984 and 1985).

In 1985, an additional form sought feedback from students on specific aspects of the competencybased approach. We designed the form with input from the Department of Family Medicine curriculum committee. It included items on the objectives, the tests, and the impact of the approach on students' study habits.

Fifteen of the 16 items used a 7-point scale with anchors at each end. For example, one item asked whether the learning objectives were clear, and used the anchors "very clear" and "not at all clear." One additional item asked students whether they preferred to receive learning objectives at the beginning of the course, before the applicable section or lecture, or after the section or lecture.

Standard student ratings for 1984 were low. OCP III received the lowest ratings for overall organization and presentation of any course in the first 2 years, with 70 percent of the students completing the rating form. The laboratories, case studies, seminars, and self-instruction materials received average or above average ratings. Student comments were divided. Some said that the competency-based approach should be dropped. Others thought that the idea was good but needed improvement.

Standard student ratings for 1985 suggested that some improvement had occurred, but still put OCP III below average for overall organization and presentations (45 percent of the students completed the form). The written comments again stated that the competency-based approach should be dropped, with some students expressing this fairly strongly. Others thought that the approach could be continued with further improvements.

These comments and ratings are interesting when compared with the results of the special questionnaire. In that questionnaire, students rated specific aspects of the approach positively: They thought that the objectives were clear, useful, and covered clinically relevant material that everyone should know; they thought that the tests were fair and clear, and accurately reflected what they knew about the material. They especially liked the prac- 
tice practical, and appreciated the opportunity to retake examinations. Students did not feel that the approach had a significant effect on how they studied or how much they retained. Nevertheless, they did not like the competency approach and would not like to see it used in other courses.

This disparity requires some explanation. Did different students complete the regular evaluation and the special form? The forms were distributed and collected at the same time, and a similar number of students (40-45 of 96) returned each form. This suggests that both forms were completed by the same group.

Perhaps student dissatisfaction stems from aspects not covered in specific items. The written comments support this view. These comments identify two sources of dissatisfaction: (1) The procedures in OCP III differ from those in all other courses, which is a source of stress for already busy students; and (2) some students are frustrated by the requirement to perform at a high level on competency-based tests ( 90 percent) when that level of performance is not reflected in a letter grade.

\section{Faculty evaluation}

The second author (MPL) asked faculty who taught in OCP III for their views on the course. All faculty making presentations in the course were contacted; 11 were interviewed for 20 to 30 minutes each. Faculty responses fell into two categories-aspects of the course, and aspects of administration.

Course aspects. All faculty expressed support for the basic teaching and testing approach. Many had used objectives before this experiment began. One faculty member liked the fact that students were required to pass each section of the course. For example, students could not fail in the Psychosocial section and, by maintaining a 70 + average overall, still pass the course.

However, faculty had different perceptions about what "competency-based" meant. Some expressed confusion about their role. A few pointed to the difficulty of identifying "must know" material in medicine, when the field itself changes so quickly. They felt uncomfortable making judgments in this area. One asked why objectives not considered to be critical are covered or tested at all. Another mentioned the lack of acceptance of the approach by students as a problem.

Some faculty did not feel that the approach was applicable to their portion of the course. These tended to be faculty who either taught for a limited amount of time or who were committed to an existing curriculum for their section.

Administrative aspects. Faculty appreciated the time and effort involved in organizing the course in a new way. Although some had reservations about the approach or suggestions for improvement, most felt that it was important to continue experimenting with new methods of teaching and evaluation.

There were some communication problems. Some faculty had not understood exactly what they were asked to do, and they did not feel that they had had sufficient opportunity to discuss it. Some did not have a clear understanding of the approach after discussing it. In the face of the enthusiasm and commitment of the course coordinator, some faculty found it difficult to discuss their reservations.

Some also had problems integrating the approach with the existing curriculum in their area. They felt that faculty in their section had devoted significant amounts of time and effort to developing their part of the curriculum. They could not change it at the request of one coordinator without extensive consultation and redevelopment. Some faculty felt that this was unnecessary; others thought that they should have greater autonomy.

Almost all faculty said that the competencybased approach should continue. They felt that 2 years was not enough time to see whether the approach would work, and that it had improved significantly in 2 years and had the potential to do so again. Many said that the innovation should be pursued if the course coordinator thought it was the right approach and had the energy to persevere.

\section{Discussion}

The approach taken in this course achieved the goal of focusing on the most critical material, as shown by student responses to the special questionnaire. Students gave high ratings to specific aspects of the innovation: the use of objectives, distribution of objectives early in the course, the opportunity to retake examinations, and the practice practical. These will remain in the course.

The goal of improving retention is more difficult to evaluate. Various methods of measuring this will be explored. Unfortunately, it will be difficult to determine whether this approach was responsible for any improvements found, because of intervening factors like later coursework and experiences in clinical settings. ${ }^{9,10}$

The problems identified all relate to the difference between OCP III and other courses. Student comments emphasize the need to ensure that OCP III is clearly organized, with easy-to-follow guidelines. Evaluation results suggest that faculty may need to go over procedures more often and more carefully with students. Greater emphasis on positive aspects of the approach may be helpful. For 
example, the opportunity for remediation and for retaking examinations could be expressed more positively and defuse the attitude of "failure" on not passing on the first attempt.

The grading issue is a difficult one. Mastery/ competency approaches seek to lower the emphasis on competitive letter grading systems and to enable each student to master the material. On the other hand, students need to be reinforced for performing well. Mastery courses are often self-paced; reinforcement is provided by allowing students to move on when a section is completed. This option is not possible in OCP III at this time.

Some students felt that 90 percent was an unreasonable level for a passing grade. If the content tested is really critical, this requirement may be justified. The 90 percent requirement applies to approximately half of the material that had previously been tested at a 70 percent level requirement. Furthermore, students had three chances to achieve that goal. These advantages must be made clearer to those objecting to this level of expectation.

Improved faculty understanding and cooperation must be addressed. Greater attention needs to be paid to individual and group understanding of the philosophy behind the approach and its application in this course. One step in this direction will be to circulate this paper to those involved. Greater understanding can lead to greater cooperation.

Some conflict with preexisting curricula is inevitable. Competency-based education offers an opportunity to examine which portions of that curricula students should be required to master, at what level of competence. Material can be presented to students without expecting them to demonstrate a high level of competence in OCP III. Faculty support for the underlying principles of competency-based education suggests that improved communication can resolve these issues.

\section{Comment}

Experience with competency-based evaluation for two years shows that the most significant disadvan- tage was the difference from the methods more commonly used. This caused increased anxiety for both students and faculty. Attempting to improve communication with both groups may be the most productive approach to gaining acceptance.

This innovation has the advantages of specifying the most critical knowledge and skills, and ensuring their mastery. Competency-based education directly confronts the difficulty in specifying what material will be most useful to the student physician. Continuation of the approach provides an opportunity for faculty to face this issue and to define medical education more clearly.

1. Dennis, M.A.: Competency-based objectives for undergraduate os teopathic clinical education. American Association of Colleges of Osteopathic Medicine, Rockville, MD, 1984

2. Guilbert, J.-J.: How to devise educational objectives. Med Educ 18:134-41, May 84

3. Muller, S.: Physicians for the twenty-first century. Report of the Project Panel on the General Professional Education of the Physician and College Preparation for Medicine. J Med Educ 59:1-208, Nov (Part 2) 1984

4. Silber, D.L., et al.: The SIU medical curriculum. Systemwide objectives-based instruction. J Med Educ 53:473-9, Jun 78

5. Mast, T.A., et al.: Medical student use of objectives in basic science and clinical instruction. J Med Educ 55:765-72, Sep 80

6. Williams, R.G., and Osborne, C.E.: Medical teachers' perspectives on development and use of objectives. Med Educ 16:68-71, Mar 82

7. Petit, P.L.: Behavioural objectives for medical auxiliary training in Tanzania-9 years' experience with an educational model. Med Educ 19:123-30, Mar 85

8. McGaghie, W.C., et al.: Competency-based curriculum development in medical education. An introduction. (Public health papers 68.) World Health Organization, Geneva, 1978

9. Melton, R.F.: Resolution of conflicting claims concerning the effect of behavioral objectives on student learning. Rev Educ Res 48:291-302, Spring 1978

10. Duchastel, P.C., and Merrill, P.F.: The effects of behavioral objectives on learning. A review of empirical studies. Rev Educ Res 43:53-69, Winter 1973

Accepted for publication in July 1986. Updating, as necessary, has been done by the authors.

Dr. Olson is assistant professor of family medicine, Department of Family Medicine, Ohio University College of Osteopathic Medicine, Athens, Ohio. Ms. Mann is coordinator of faculty development in the Department of Educational Development and Resources, OUCOM.

Dr. Olson, OUCOM, 331 Grosvenor, Athens, Ohio 45701 


\section{Books}

continued from page $\mathbf{2 2 0 / 4 8}$

\section{management.}

As one peruses the chapters on respiratory system, neurogenic bladder, and gastrointestinal management, one is impressed with the various new modalities used in modifying the secondary sequelae of these compromised systems. Considerable literature references are included so that the reader can easily locate the necessary data on management follow-up. In my own special interest of pain control, I was gratified to see a very detailed review of pain physiology, as well as a differentiation of pain in spinal cord injury. Hyperalgesic border reactions, central pain syndromes, burning pains, phantom sensations, painful visceral-like sensations and painful events in visceral disease are all covered in considerable depth. The treatments advocated include pharmacologic, electroanalgesic, anesthesiologic, and surgical, with adequate comment upon each. The new psychologic approach of behavior modification, hyp-

\section{INTERNAL MEDICINE RESIDENCY}

Opening beginning July, 1987 in an expanding Internal Medicine program.

Well-covered subspecialty areas include:

- Gastroenterology

- Pulmonary Medicine/ Critical Care

- Cardiology

- Hematology/Oncology

- Neurology

- Rheumatology

- General Internal Medicine

Apply to:

Jonathan W. Karol, D.O.

Director of Medical Education

Osteopathic Hospital of

Maine, Inc.

335 Brighton Avenue

Portland, ME 04102

Phone: 207-772-3756 nosis, and cognitive-relaxation techniques are likewise discussed in considerable clinical detail with adequate literature references. A full discussion of the management of spasticity is preceded by adequate physiological material and is followed by various pharmacologic and surgical techniques.

Heterotopic ossification following spinal cord injury is a new and troublesome complication in this field. It involves abnormal anatomic loci infiltration with new bone deposits, usually in soft tissue areas. Prolonged posttraumatic longevity permits this complicating side effect to develop. This topic is discussed in full physiologic detail, and is followed by a review of pharmacologic and surgical treatment approaches. This chapter alone establishes the uniqueness of this book, since previous rehabilitation texts have only touched upon this subject.

Physical therapy, which is the keystone to most rehabilitation programs, is covered in very physiologic orientation with considerable critique on muscle strength, functional respiratory capacity, and myoelectric stimulation assistance. The remaining chapters on occupational therapy, resocialization, and sexual function complete the book.

In summary, this book is a very valuable contribution to the field of rehabilitation medicine in spinal cord injury management. It should be available in every hospital library as an important reference text. It is, however, a book primarily oriented toward physiatrists and their colleagues in the rehabilitation field. It is not a book for the general practitioner, general surgeon, or internist.

HENRY NEMEROF, D.O., FAOCRM

Consulting Physician

Department of Physical Medicine and Rehabilitation

Metropolitan Hospital

Philadelphia, Pennsylvania

\section{Respectful treatment}

By Mortin R. Lipp. Ed. 2, pp. 331. Elsevier Science Publishing $\mathrm{Co}$, Inc., 52 Vanderbilt Ave., New York 10017, 1986.

Dr. Lipp's preface offers an honest and provocative introduction to a book filled with transformational insight. He states, "Many of our patients feel alien in the medical environment we take for granted. They don't know the language; they don't fully comprehend the culture; they feel awkward, ignorant, powerless, and defensive- even separate from whether they are sick or well. All in all, it's not a setting designed to bring out the best in them. Yet, treating the patient with respect, and being accorded respect in return can make the process not only more endurable but even enjoyable."

After giving us an uplifting springboard for exploring the world of clinical self-improvement, he pulls no punches. The first chapter, on problem patients, includes a theoretic doctor-patient interaction in which the reader is asked how to recommend most sensitively that a patient undergo a liver biopsy. There is no correct answer, but the exercise is stimulating and thought-provoking. Other categories include the angry patient; the dependent, passive patient; the complaining, demanding patient; the denying patient; the overly affectionate patient; and the chronic schizophrenic.

The second chapter, entitled "Tough places to work," includes mini-essays on skill descriptions for working in outpatient clinics, including rapid bonding, time management, and assessing for compliance. Included in the description is "finding soulful satisfactions," where Dr. Lipp states, "If you are lucky, you will learn to take time with patients, not so much for their sake as for your own; helping them to feel better not merely because of your technical skills, but because of who you are as a person."

Other chapters include psychiatric emergencies, the patient's right to self-determination, confused states, emotional aspects of major disease categories, psychosocial condition disguised as physical illness, medical conditions in psychiatric disguise, consultations and referrals, and calling for help. In discussing coping and the occupational hazards of physicianhood, Lipp states, "At various stages in my training, I was told implicitly or explicitly if you don't know everything, you will kill continued on page $264 / 108$ 



\section{WHEN EFFICACY IS YOUR FIRST CONCERN.}

There may be times when price and convenience are considerations in your choice of an NSAID. But when your primary concern is anti-arthritic efficacy, consider TOLECTIN DS tolmetin sodium.

TOLECTIN DS reduces arthritis pain and inflammation while improving functional capacity - as effectively as indomethacin. ${ }^{1}$

Yet, long-term, double-blind studies show that TOLECTIN DS, unlike indomethacin, rarely causes CNS side effects such as dizziness and light-headedness. The most frequent side effects were $\mathrm{Gl}$ related in both treatment groups.

So, when your first concern is anti-arthritic efficacy, your first choice should be TOLECTIN DS-as effective as indomethacin, but often gentler.

1. Caldwell J, Brandon ML, Franz KH, et al: A double-blind comparison of the efficacy and side effect lia bility of tolmetin and indomethacin. Presented at a symposium, Tolmetin: A New Non-Steroidal Anti Inflammatory Agent. Washington, DC, April 1975. Excerpta Medica, 1976, pp 57-70.

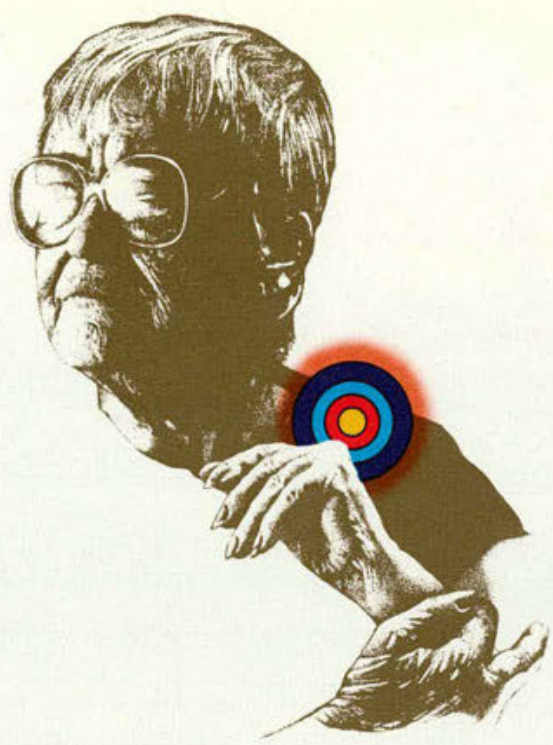

\section{For Arthritis}

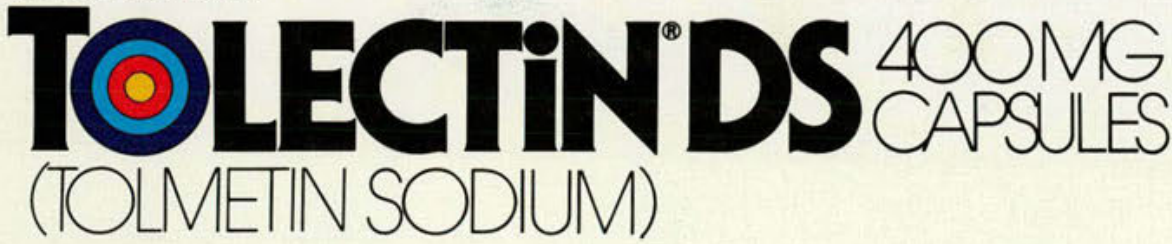

\section{ASEFFECTIVE AS INDOMETHACIN..OFTEN GENTLER}

\begin{abstract}
TOLECTIN* (tolmetin sodium)
The following is a brief summary only. Before prescribing, see complete prescribing information in TOLECTIN product labeling.

Contraindications: Anaphylactoid reactions have been reported with TOLECTIN as with other nonsteroidal anti-inflammatory drugs. Because of the possibility for cross-sensitivity. TOLECTIN should not be given to patients in whom aspirin and other nonsteroidal anti-inflammatory drugs (particularly zomepirac sodium) induce symptoms of asthma, rhinitis, urticaria or other symptoms of allergic or anaphylactoid reactions. Patients experiencing anaphylactoid reactions on TOLECTIN should be treated with conventional therapy, such as epinephrine, antihistamine and/or steroids.

Warnings: Give under close supervision to patients with a history of Warnings: Give under close supervision to patients with a history
upper gastrointestinal tract disease and only after consulting the "Adverse Reactions" section. Peptic ulceration and gastrointestinal bleeding, sometimes severe, have been reported. If TOLECTIN must be given to patients with active peptic ulcer, closely supervise for signs of ulcer perforations or severe gastrointestinal bleeding

Precautions: Patients who develop visual disturbances during treatment with TOLECTIN should have ophthalmologic evaluations and follow-up.

Cases of acute interstitial nephritis with hematuria, proteinuria, and occasionally nephrotic syndrome have been reported. Closely monitor patients with impaired renal function; they may require lower doses. In patients with prerenal conditions leading to a reduction of renal blood flow or blood volume, administration of an NSAID may precipitate overt renal decompensation. Patients at greatest risk are those with hear failure, liver dysfunction, those taking diuretics, and the elderly.

TOLECTIN prolongs bleeding time. Patients who may be adversely

affected by prolongation of bleeding time should be carefully observed when TOLECTIN is administered.

In patients receiving concomitant TOLECTIN-steroid therapy, any reduction in steroid dosage should be gradual to avoid the possible complications of sudden steroid withdrawal.

TOLECTIN should be used with caution in patients with compromised cardiac function, hypertension, or other conditions predisposing to fluid retention.
\end{abstract}

A patient with symptoms and/or signs suggesting liver dysfunction, or in whom an abnormal liver test has occurred, should be evaluated for evidence of the development of more severe hepatic reactions while on therapy with TOLECTIN. Severe hepatic reactions, including jaundice and fatal hepatitis, have been reported with TOLECTIN as with other nonsteroidal anti-inflammatory drugs. Although such reactions are rare, if abnormal liver tests persist or worsen, if clinical signs and symptoms consistent with liver disease develop, or it systemic manifestations occur (e.g. eosinophilia, rash, etc.) discontinue TOLECTIN.

Carcinogenesis, Mutagenesis, Impairment of Festility - Tolmetin sodium did not possess any carcinogenic liability, mutagenic potential or impairment of tertility in standard in vitro tests and/or in tests in or impairment of fertility in standard in vitro tests and/or in tests i animals. Effects on parturition (including increased incidences of dystocia and delayed parturition
other prostaglandin inhibitors.

Pregnancy - TOLECTIN has not been studied in pregnant women. Drugs in this class have known effects on the fetal cardiovascular system which may cause constriction of the ductus arteriosus in utero during the third trimester of pregnancy, which may result in persistent pulmonary hypertension of the newboin. Therefore, TOLECTIN should

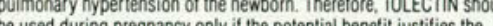
be used during pregnancy

Nursing Mothers - Because TOLECTIN is secreted in human milk Nursing Mothers - Because TOLECTIN is secreted in human mik,
nursing should not be undertaken while a patient is on this drug. Pediatric Use - The satety and effectiveness of TOLECTIN to children under 2 years of age have not been established.

Drug Interactions - Increased prothrombin time and bleeding have been reported in patients on concomitant TOLECTIN and wartarin therapy; caution should be exercised when administering TOLECTIN to patients on anticoagulants.

Drug/Laboratory Test Interaction-Metabolites of tolmetin in urine have been found to give positive tests for proteinuria using tests which rely on acid precipitation as their endpoint. No interference is seen in the tests for proteinuria using dye-impregnated commercially available reagent strips.

Drug-Food Interaction - In a controlled single dose study, administration of TOLECTIN with milk had no effect on peak plasma tolmetin concentration, but decreased total tolmetin bioavailability by $16 \%$. When TOLECTIN was taken immediately after a meal, peak plasma tolmetin concentration and total bioavailability were reduced by $50 \%$ and $16 \%$, respectively.
Adverse Reactions: Incidence Greater Than $1 \%$ - The following adverse reactions which occurred more frequently than 1 in 100 were reported in controlled clinical trials.

Gastrointestinal: Nausea (11\%), dyspepsia, " gastrointestinal distress," abdominal pain." diarchea "flatulence " vomiting "

constipation, gastritis, and peptic ulcer.

Body as a Whole: Headache." asthenia * chest pain

Body as a Whole: Headache," asthenia," chest pain

Central Nervous System: Dizziness," drowsiness, depression Central Nervous System: Dizziness," drowsiness,
Metabolic/Nutritional: Weight gain," weight loss" Metabolic/Nutritional: Weight Dermatologic: Skin irritation Special Senses: Tinnitus, visual disturbance Hematologic: Small and transient decreases in hemoglobin and hematocrit not associated with gastrointestinal bleeding have occurred. Urogenital: Elevated BUN, urinary tract infection - Reactions occurring in $3 \%$ to $9 \%$ of patients treated with TOLECTIN. Reactions occurring in fewer than $3 \%$ of the patients are unmarked. Incidence Less Than 1\% (Causal Relationship Probable) -

Gastrointestinal: Gastrointestinal bleeding with or without evidence of peptic ulcer, glossitis, stomatitis, hepatitis, liver function abnormalities Body as a Whole: Anaphylactoid reactions, fever, lymphadenopathy. serum sickness

Hematologic: Hemolytic anemia, thrombocytopenia, granulocylopenia, agranulocytosis

Cardiovascular: Congestive heart tailure in patients with marginal cardiac function

Dermatologic: Urticaria, purpura, erythema multiforme, toxic epidermal necrolysis

Urogenital: Hematuria, proteinuria, dysuria, renal failure Incidence Less Than 1\% (Causal Relationship Unknown)-

Body as a Whole: Epistaxis
Specia/ Senses: Optic neuropathy, retinal and macular changes

Special Senses: Optic neuropathy, retinal and macular changes
Full directions for use should be read before administering or prescribing.

For information on symptoms and treatment of overdosage, see full prescribing information. MCNEIL

$11 / 20 / 85$ 


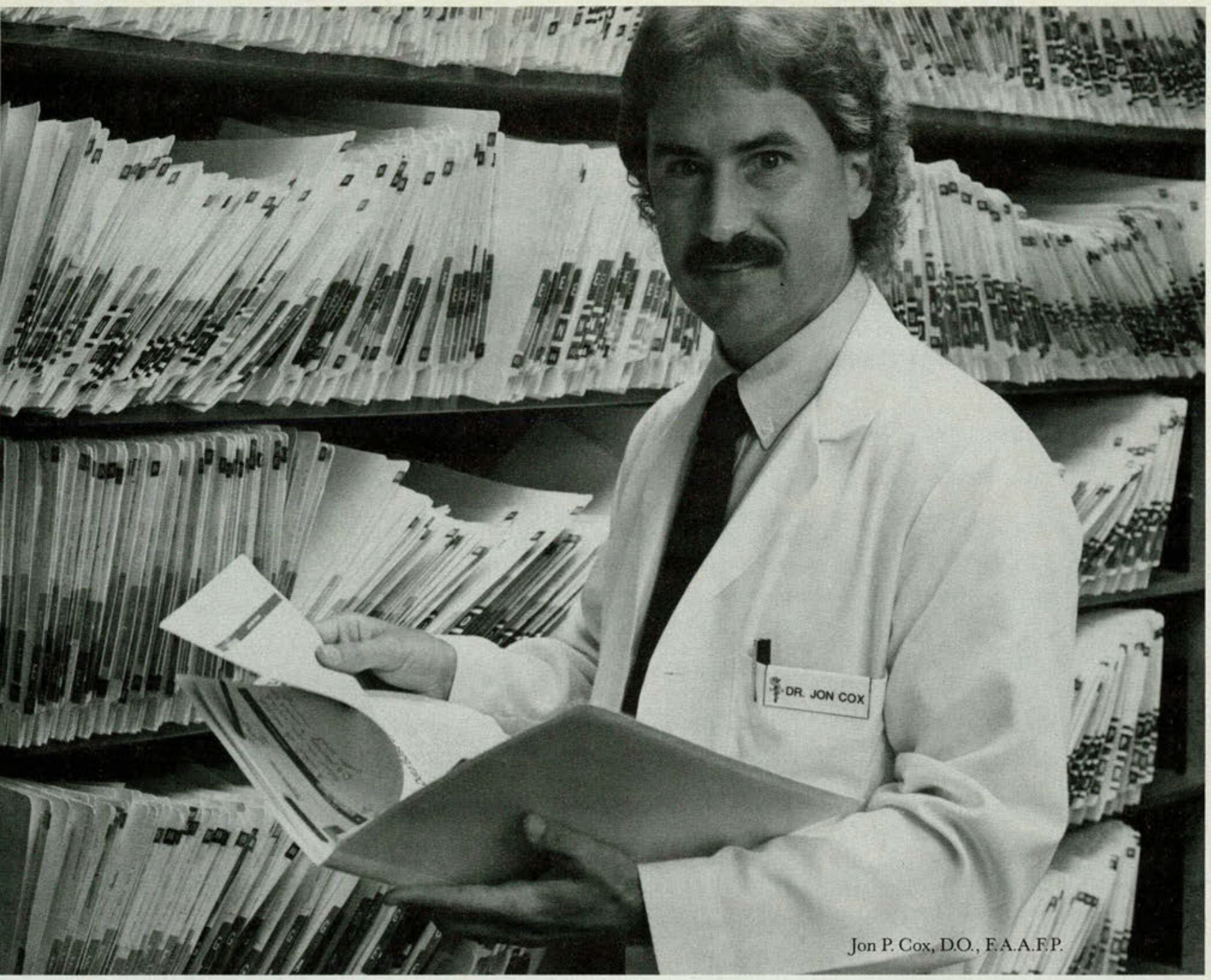

\section{6}

\section{he best way to build a practice is with a built-in} practice." A built-in management teamand advanced technology... The involvement of primary care - and the excitement of acute care... A professional life-and room for a personal one... A practice-not paperwork...

These are only a few of the advantages being realized by the physicians starting practices with Humana MEDFIRST.

Humana MEDFIRST is a nationwide network of health care facilities with an innovative system that makes primary care easier for both physician and patient.

Each facility is a self-contained, free standing medical office equipped with everything-including staff-needed for primary and acute care. It represents a new way for consumers to have improved access to high quality, routine care.

In these days of competition for good positions, Humana MEDFIRST offers an excellent alternative. There is not the financial risk of opening a practice, and it no longer takes years to build. For those just finishing residency, Humana MEDFIRST presents an opportunity to start working with medical professionals right away.

The facility manager and full and part-time staff of nurses, customer service representatives, lab and $\mathrm{x}$-ray technicians are there as a team to support the physician.

For those starting a practice, the Humana MEDFIRST organization can provide powerful support backed by years of accumulated knowledge in many areas.

We are taking care of business so that our physicians can attend to the medical needs of their patients.

So if you're looking for a dynamic, exciting place to practice medicine, call today toll-free 1-800-662-2272, or send your curriculum vitae to Rod Joseph, Humana MEDFIRST, Department J, 500 W. Main St., Louisville, KY 40202.

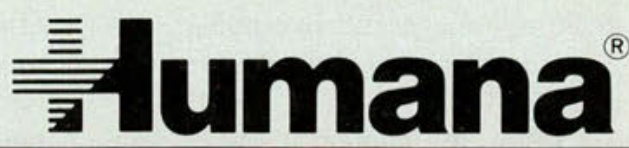
MEDFIRST

Physician Care 
someone. If you don't know everything, you will be a lousy doctor and you don't belong in clinical medicine. That, of course, is the Big Lie-and probably the source of more unhappiness and guilt and personal suffering in physicians than all other misbeliefs put together."

Respectful Treatment is a colorful, at times philosophic, and highly practical source of problem-solving that should be required reading for every medical student and physician.

ROBERT A. NORMAN, D.O. Arlington, Massachusetts

\section{Emotional disorders in physically ill patients}

Edited by Robert Roessler and Norman Decker. Pp. 269. Human Sciences Press, Inc., 72 Fifth Avenue, New York 10011, 1986 , $\$ 26.95$.

Emotional disorders in physically ill patients is multiauthored by a distinguished collection of academic consultation/liaison psychiatrists. The text begins with an excellent description of what a $\mathrm{C} / \mathrm{L}$ psychiatrist is and what he or she does. This is one of the best descriptions of the subspecialty I have ever read.

The book is divided into three primary sections: Part I, "Problems in primary care medicine;" Part II, "Surgical problems;" and Part III, "Chronic illness." Part I includes six chapters covering topics such as "Crises in medical care," "Organic brain syndrome," "Psychopharmacologic treatment of physically ill patients," "Patients with pain," "Sleep," and "The diagnosis and management of hypochondriasis." This section comprises over one half of the book. Part II covers "Acute adjustment to trauma," "Psychological aspects of coronary bypass surgery," and "Psychiatric problems in $\mathrm{Ob} /$ Gyn patients." The final section includes discussions on Parkinson's disease, cancer, and psychologic adjustment to physical trauma and disability.

I liked the choice of topics, and found them to be representative of the more important areas of poten- tial $\mathrm{C} / \mathrm{L}$ psychiatric intervention.

The stated goals of the editors were to have the reader come away with "a more sensitive appreciation of what it means to be a patient and a greater appreciation of the importance of his/ her own role to the welfare of patients." Additionally, they intended to give the clinician "a greater understanding of the effects of patient's previous experiences, the effects of the nature of an illness, and the effects of the hospital environment on the patient." Finally, they felt an appreciation and knowledge of these issues would help reduce distress and behaviors complicating and prolonging patient recovery. If the reader is able to achieve these objectives through reading the book, they owe a debt of gratitude to the authors. Just being aware of the existence of these points is a major step toward being a more empathic, caring clinician.

Overall, I found the book's content to be quite excellent. In general, a biopsychosocial approach was used throughout. Like many multiauthored texts, there was a lack of consistency in style. Some chapters utilized case reports, some featured charts and graphs, and others contained straight narrative. There was a large discrepancy in the number of references cited at the conclusion of each chapter, ranging from 93 citations in the psychopharmacology chapter to 2 in the Parkinson and 3 in the cancer chapters. I would have preferred to have each author list 5 to 10 references, including a good review article with an extensive reference list.

For the most part, the text was clear, coherent and easy to read. I did not, however, like the way footnotes were handled. At the end of the sentence, the author and date of the reference were listed in parentheses. Stylistically, I found this was awkward and interfered with otherwise good writing.

This book is appropriate for interns, residents, and practicing clinicians in primary care, internal medicine, surgery, and psychiatry. Senior medical students could also benefit from reading this book and develop "good habits" from the start.

As a general consultation/liaison continued on page $\mathbf{2 6 5} / 111$
Gebauer Chemical Co. Cleveland, $\mathrm{OH} 44104$

Stretchand-Spray Technique... Tennis
Elbow...

Myofascial trigger points* in the supinator muscle often are responsible for the painful condition known as "Tennis Elbow." Pain from trigger points in the supinator is referred to the lateral epicondyle, and surrounding lateral aspect of the elbow. Pain is also referred dorsally down the forearm to the web of the thumb. Gebauer's Fluori-Methane Spray, when used in conjunction with the stretch-and-spray technique can, in acute cases, inactivate the trigger points and relieve the patient's pain. In chronic cases adjacent muscles are usually involved and also must be treated.

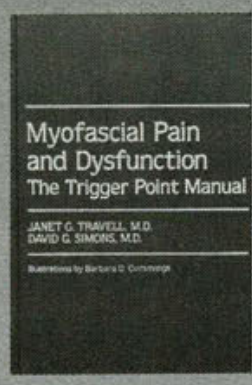

For more information about supinator trigger points and myofascial pain, consult The Trigger Point Manual:** This bestselling new reference manual offers the most comprehensive explanation of diagnosis and treatment of the myofascial pain syndromes for the upper half of the body. Detailed "how to" procedures with full illustrations combine to make this book a "must" for healthcare professionals.

Written by: Janet G. Travell M.D. Emeritus Clinical Professor of Medicine, The George Washington University School of Medicine. Washington, D.C.

and

David G. Simons M.D. Clinical Professor, Department of Physical Medicine and Rehabilitation, University of California Irvine, Irvine, CA.

llustrated by: Barbara D. Cummings Published by: Williams and Wilkins, Baltimore/London, 1983. 



\section{EXPANDING INTERNAL MEDICINE RESIDENCY PROGRAMS}

\section{FIRST, SECOND, THIRD YEAR POSITIONS AVAILABLE}

\section{BEGINNING JULY 1987}

OTHER RESIDENCY PROGRAMS
ANESTHESIA
ENT
GENERAL PRACTICE
GASTROENTEROLOGY
INTERNAL MEDICINE
OBSTETRICS
OPHTHALMOLOGY
ORTHOPEDICS
PATHOLOGY
PULMONARY
RADIOLOGY
SURGERY
UROLOGY
SUBSPECIALTY RESIDENCIES
GASTROENTEROLOGY
PULMONARY

OTHER RESIDENCY PRograms

ENT

General Practice

GASTROENTEROLOGY

OPHTHALMOLOGY

ORTHOPEDICS

RADIOLOGY

SURGERY

PULMONARY

\author{
EdUCATIONAL PRograms \\ Daily Guest Lecturers \\ Monthly Seminars \\ MORNING REPORTS \\ Journal CLubs
}

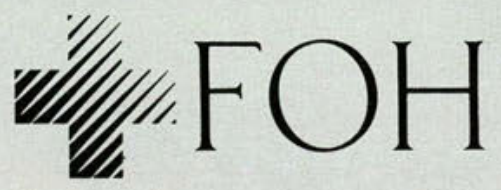

TO OBTAIN AN APPLICATION OR MORE INFORMATION ABOUT OUR PROGRAMS, CONTACT:

Flint Osteopathic Hospital Director of Medical Education 3921 BeEcher Road

FLINT, MICHIGAN 48502

(313) $762-4707$

\section{ASSOCIATE DEAN FOR CLINICAL TRAINING/ POSTDOCTORAL EDUCATION}

The West Virginia School of Osteopathic Medicine invites applications and nominations for the position of Associate Dean for Clinical Training/Postdoctoral Education. The Associate Dean is an administrative officer of the School charged with developing and evaluating the entire clinical portion of the off-campus curriculum. This position also has the responsibility to establish and supervise Postdoctoral Educational Programs. The Associate Dean reports directly to the Dean for Academic Affairs.

Qualified candidate must be a Board Certified osteopathic physician, have both academic and administrative experience, be licensed to practice osteopathic medicine in the State of West Virginia and must be willing to travel. Salary is negotiable.

Interested candidates should submit complete Curriculum Vitae to:

Associate Dean for Clinical Training Search Committee c/o Human Resources Office

West Virginia School of Osteopathic Medicine

400 North Lee Street

Lewisburg, West Virginia 24901

Deadline for accepting application is April 15, 1987. 
text, I do not think it is as good as Guggenheim's Manual of consultation and emergency psychiatry, but it is certainly worthwhile reading with valuable points to make.

DAVID A. BARON, D.O.

Consultation/Liaison Psychiatry

University of Southern California

School of Medicine

Los Angeles, California

\section{Books received}

New books received by the Andrew Taylor Still Memorial Library are acknowledged below. Those of greatest interest to our readers will be reviewed later.

Trauma: Clinical care and pathophysiology. Edited by Lewis M. Flint, Hiram C. Polk, Jr., and J. David Richardson; pp. 597, with illus.; Year Book Medical Publishers, Inc., 35 E. Wacker Drive, Chicago 60601, 1987 . $\$ 65.00$

Cardiac arrhythmias: Their mechanisms, diagnosis, and management. (Definitive text for all physicians who deal with patients with rhythm disorders.) Edited by William J. Mandel; ed. 2, pp. 861, with illus.; J.B. Lippincott Company, East Washington Square, Philadelphia 19105, $1987, \$ 75.00$.

Essentials of skeletal radiology. Vols. I and II. Edited by Lindsay J. Rowe and Terry R. Yochum; pp. 537 (Vol. I), 1136 (Vol. II), with illus.; Williams \& Wilkins, 428 E. Preston Street, Baltimore 21202, $1987, \$ 150.00$ set.

Clinical electrocardiography: A primary care approach. (For primary care physicans, medical students, and residents. Contains review exercises.) Edited by $\mathrm{R}$. Whitney Curry, Jr., and Ken Grauer; pp. 544, with illus:; Medical Economics Books, Oradell, NJ 07649, 1987, \$24.95 (paper).

Physical examination of the mus culoskeletal system. Edited by Melvin Post; pp. 311, with illus.; Year Book Medical Publishers, Inc., 35 E. Wacker Drive, Chicago 60601, 1987, \$59.95.

Bladder reconstruction and continent urinary diversion. (An overview of intestinal use in urology, including advances in bladder substitution.) Edited by Lowell R. King, Anthony R. Stone, and George D. Webster; pp. 379, with illus.; Year Book Medical Publishers, Inc., 35 E. Wacker continued on page $267 / 114$

\section{BOSTON}

\section{GENERAL PRACTICE RESIDENCY}

New one year program available July 19872 positions (one already filled). Strong consideration for candidate desiring Boston area practice. For further details Richard Levrault D.O., Director of Medical Education or Timothy Lowney D.O., Program Director.

(617) $522-4300$

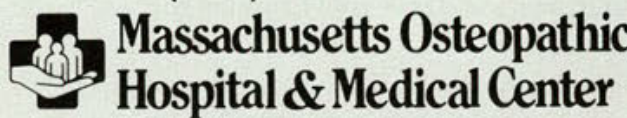

222 South Huntington Avenue Boston, MA 02130

\section{CHARLES C THOMAS • PUBLISHER}

NeW! MEDICAL TREATMENT OF NECK AND BACK PAIN by James W. Fisk. The author provides a sound basis on which to develop skills in history taking, examination, and treatment. Scheuermann's disease and its importance in premature spinal aging is discussed; trigger points, overloaded coping system syndrome, and acute low back injury are covered. ' $87, \$ 38.25$

MUSCULOSKELETAL MANIPULATION: Evaluation of the Scientific Evidence by Jerome $\mathbf{S}$. Tobis and Fred Hoehler. This monograph succinctly reviews and evaluates current information on how musculoskeletal manipulation works and which patients benefit from the procedure. History, techniques, indications and contraindications are included. ' $86, \$ 21.75$

Empirical Approaches to the VALIDATION OF SPINAL MANIPULATION edited by A. A. Buerger and Philip E. Greenman. This review of the state of research into spinal manipulation covers: the biomechanics of the back, characteristics of back pain, randomized clinical trials of manipulation for low back pain, and overviews of back pain and manual medicine. ' $85, \$ 38.25$

THE HEALTHY LOWER BACK: Laying the Foundation Through Proper Lifting, Sitting, and Exercise by Dennis Zacharkow. The author, a physical therapist at the Mayo Clinic, shows how to correct the improper lifting technique and poor sitting posture that are the major contributing factors in lower back disorders. Remedial approaches and exercises are detailed. '84, \$18.50

We fill all orders promptly • Books sent on approval MasterCard, Visa \& prepaid orders sent postpaid

Catalog sent on request • Write or call (217) 789-8980 